IOS Press

\title{
Endophytic colonization and pest management potential of Beauveria bassiana in strawberries ${ }^{1}$
}

\author{
Surendra K. Dara ${ }^{\mathrm{a}, *}$, Sudha R. Dara ${ }^{\mathrm{b}, 2}$ and Sumanth S. Dara ${ }^{\mathrm{c}}$ \\ ${ }^{\mathrm{a}}$ University of California Cooperative Extension, San Luis Obispo, CA, USA \\ ${ }^{\mathrm{b}}$ Cachuma Resource Conservation District, Santa Maria, CA, USA \\ ${ }^{\mathrm{c}}$ Stockdale High School, Bakersfield, CA, USA
}

Received 17 October 2013; accepted 14 November 2013

\begin{abstract}
.
BACKGROUND: Chemical pesticides are predominantly used for managing various pests on strawberries in California. Biological control is limited to the release of predatory mites against spider mites. Predominant use of chemical pesticides does not provide complete and satisfactory control of certain pests and interferes with biological control. Microbial control is an unexplored area in California strawberries. Limited pest control with current practices, risk of pesticide resistance, and concern for environmental safety associated with excessive use of chemical pesticides prompt the search for safer and effective alternatives. Entomopathogenic fungus, Beauveria bassiana (Balsamo) Vuillemin and a botanical pesticide, azadirachtin are active against most of the strawberry pests. Additionally, B. bassiana is known to endophytically colonize some plant species and provide protection against herbivore damage. Identifying non-chemical alternatives is a critical area in strawberry pest management.

OBJECTIVE: Explore the potential of $B$. bassiana against strawberry pests and the ability to colonize strawberry plants.

METHODS: Efficacy of reduced rates of chemical pesticides, B. bassiana, and azadirachtin against adult lygus bug, Lygus hesperus Knight were determined in laboratory assays. Greenhouse and laboratory studies were conducted to determine endophytic colonization potential of B. bassiana in strawberry plants. Efficacy of B. bassiana against L. hesperus was determined in small plot field trial in strawberries and against other pests in greenhouse strawberries was also studied.

RESULTS: Certain combinations of chemical pesticides and B. bassiana at reduced rates improved L. hesperus mortality. Beauveria bassiana colonized and persisted in various strawberry tissues for up to 9 weeks after inoculation. No impact of the $B$. bassiana on L. hesperus numbers was seen in the field study, but was found effective, along with azadirachtin, against some pests in the greenhouse study.
\end{abstract}

CONCLUSION: Non-chemical alternatives such as B. bassiana and azadirachtin have a good potential for strawberry pest management.

Keywords: Aphid, Beauveria bassiana, endophyte, Frankliniella occidentalis, Lygus hesperus, microbial control, Tetranychus urticae, Trialeurodes vaporariorum, strawberry

\section{Introduction}

Lygus bug (Lygus hesperus Knight), twospotted spider mite (Tetranychus urticae Koch), western flower thrips [Frankliniella occidentalis (Pergande)], and greenhouse whitefly [(Trialeurodes vaporariorum (Westwood)] are important strawberry pests in the California Central Coast area. While L. hesperus and T. urticae are considered

\footnotetext{
${ }^{1}$ Paper presented at 2nd International Strawberry Congress, Hoogstraten, Belgium, Sept. 4-6, 2013.

${ }^{2}$ Present Address: Comprehensive Blood Cancer Center, Bakersfield, CA 93309, USA.

${ }^{*}$ Corresponding author: Surendra K. Dara, 2156 Sierra Way, Ste. C, University of California Cooperative Extension, San Luis Obispo, CA 93401, USA. Tel.: +1 805 7882321; Fax: +1 805781 4316; E-mail: skdara@ ucdavis.edu.
} 
as major pests, $T$. vaporariorum has become a major concern in the recent years as a pest and a vector of an important viral disease, pallidosis-related decline [8]. Various species of aphids including the green peach aphid [(Myzus persicae (Sulzer)], the melon aphid (Aphis gossypii Glover), the potato aphid [(Macrosiphum euphorbiae (Thomas)], and the strawberry aphid [(Chaetosiphon fragaefolii (Cockerell)] also occur at low numbers. However, as a vector of the pallidosis disease, they have become a target of pesticide treatments. Beauveria bassiana (Balsamo) Vuillemin is a naturally occurring soilborne fungus that is pathogenic to several pests [16, 17, 21, 24, 28].

Azadirachtin is a phytochemical that belongs to the limonoid group. It is extracted from the seed of the neem tree (Azadirachta indica A. Juss.) and acts as a feeding deterrent and insect growth regulator [18]. Azadirachtin is also known to reduce longevity and interrupt reproduction by affecting ovarian development, fecundity, and fertility [2, $13,23]$.

Various formulations of $B$. bassiana and azadirachtin are commercially available for both conventional and organic farming. Azadirachtin is used by strawberry farmers to some extent in organic farming, but B. bassiana is generally not used. Entomopathogenic fungi like B. bassiana can be potential components of integrated pest management in strawberries because of mild weather conditions in the strawberry growing regions in California. Moderate temperatures (mean ranging from $10-21^{\circ} \mathrm{C}$ ), good rainfall $(36-60 \mathrm{~cm}$ annually), foggy conditions, and condensation on the foliage are common in this region and provide ideal environment for the entomopathogenic fungi to perform well. A previous report on field studies conducted in New York indicated that early application of B. bassiana was effective in controlling the tarnished plant bug, L. lineolaris [14]. However, no information is available on its effective use against strawberry pests especially in California. Beauveria bassiana is known to endophytically colonize (growing within the plant without causing any damage or disease) corn [4] and banana [3] and provide protection against the pest insects. If this fungus can colonize strawberries and demonstrate such effect on herbivores, it could be applied through drip irrigation or through transplant root dipping at the time of planting.

Biological pesticides are generally not preferred by farmers because of their preceived low efficacy compared to chemical pesticides. In contrast to an immediate knock down effect seen from some chemical pesticides, entomopathogenic fungi can take up to 3-5 days to kill infected insects. Efficacy of entomopathogenic fungi could be increased by applying along with low rates of chemical pesticides where the chemicals can weaken the insect or promote fungal growth to aid in the infection process [10, 11]. This strategy can reduce the use and possibly extend the life of effective chemical pesticides while promoting the efficiency of microbial control agents.

In an effort to improve the integrated pest management for strawberries in California, various studies were conducted to evaluate the potential of $B$. bassiana and azadirachtin as alternatives to chemical pesticides.

\section{Material and methods}

\subsection{Beauveria bassiana with reduced rates of insecticides against L. hesperus}

In laboratory bioassays conducted in 2010, B. bassiana and 1/5th the label rate of commonly used chemical insecticides and azadirachtin were tested alone and in combination against adult $L$. hesperus. For the laboratory assays, a much lower concentration of $B$. bassiana than the field rate is sufficient to achieve $100 \%$ mortality. So $B$. bassiana was administered at $0.2 \mathrm{lb}(86.2 \mathrm{~g}) / \mathrm{ac}$ or $1 \times 10^{7} \mathrm{conidia} / \mathrm{ml}$ compared to $0.5-2 \mathrm{lb}(226.8-907.2 \mathrm{~g}) / \mathrm{ac}$ field application rate. Treatments included 0.8 oz/ac of thiomethoxam (Actara ${ }^{\circledR} 25 \%$ ai), 0.4 qrt $(378.5 \mathrm{ml}) / \mathrm{ac}$ of azadirachtin (AzaDirect $^{\circledR} 1.2 \%$ ai), $2.1 \mathrm{fl} \mathrm{oz}(62.1 \mathrm{ml}) / \mathrm{ac}$ of fenpropathrin (Danitol ${ }^{\circledR} 2.4 \mathrm{EC} 30.9 \%$ ai), $0.2 \mathrm{pt}(94.6 \mathrm{ml}) / \mathrm{ac}$ of naled (Dibrom ${ }^{\circledR} 8$ Emulsive 62\% ai) and B. bassiana (BotaniGard 22WP) alone and with each other. A $100 \mathrm{ml}$ solution at respective treatment rates was prepared. Each treatment was administered to 10 1.5-2 day old adult $L$. hesperus from a laboratory colony. Insects were anaesthetized using $\mathrm{CO}_{2}$ and were dipped in abovementioned treatment solutions. Each insect was carefully transferred to a 5 dram plastic vial and provided with freshly cut green beans. Insects were secured in the vials with a sterile foam plug and incubated in a growth chamber at $25^{\circ} \mathrm{C}$ and $14: 10 \mathrm{~L}: \mathrm{D}$ photoperiod. Beans were replaced every other day with fresh ones and mortality was monitored daily for 5-6 days. Cadavers were surface sterilized and inoculated on modified oatmeal dodine agar (ODA) medium for the emergence of B. bassiana. Cumulative daily mortality and total mortality after correcting for control mortality using Abbott's formula were 
determined [1]. Data were analysed using general linear model of ANOVA and significant means were separated using Tukey's HSD test.

\subsection{Endophytic colonization of B. bassiana in strawberry plants}

A preliminary study was conducted in 2010 to evaluate different inoculation methods that included mixing of dry conidia of B. bassiana conidia with the potting medium, vermiculite; dipping strawberry roots in conidial suspension prior to planting; and pouring conidial suspension at the base of a potted plant. Use of conidial suspensions appeared to be more effective than mixing dry conidia in the potting medium [8]. A second assay was conducted by pouring conidial suspension at the plant base using different application rates- $1 \times 10^{9}, 1 \times 10^{10}$ or $1 \times 10^{11}$ conidia in $200 \mathrm{ml}$ of water. SilWet L-77 (Helena Chemical Company, Collierville, TN) was used as a surfactant at $0.01 \%$ concentration. Conidia of a commercial isolate (GHA) and a California isolate (SfBb1) that were multiplied in the lab on solid medium were evaluated in this study. Each treatment had four plants of the strawberry cultivar Albion potted in vermiculite. Four untreated plants were used as controls. To determine the endophytic colonization of the fungus, plant tissue was collected 1, 3, 6, and 9 weeks after inoculation. Roots and aerial parts that included petiole or pedicel, leaf lamina, calyx, or sepal from each plant were collected on each sampling date. Plant material was surface-sterlized in 3\% sodium hypochlorite solution for $3 \mathrm{~min}$ followed by rinsing in distilled water for $1 \mathrm{~min}$ three times. Plant material was blotted dry using sterile, autoclaved paper towels under laminar flow hood. From each plant, two roots, petioles, and leaflets were used and from each part, two $2 \mathrm{~mm}$ pieces were excised using a sterile scalpel and placed on ODA in Petri plates. Plates were sealed with paraffin film and incubated at $25^{\circ} \mathrm{C}$. Fungal emergence and growth from the plant material was periodically observed under microscope. Surface-sterilization ensured that B. bassiana grew out of the tissues was not from external contamination. As an added precaution, $10 \mu \mathrm{L}$ of the final rinsate after surface-sterilization was also plated on ODA. Proportion of plant parts with endophytic colonization of B. bassiana at different time intervals was determined. Data were analysed using general linear model of ANOVA and Tukey's HSD test was used to separate significant means.

\subsection{Efficacy of B. bassiana against strawberry pests in the field}

In a preliminary study conducted on a commercial organic strawberry field in Santa Maria, California in 2010, an organic formulation of $B$. bassiana $\left(\right.$ Mycotrol- $\mathrm{O}^{\circledR}$ ) was applied to an organic strawberry (cultivar Albion) field at 1 and 2 qrt $(946.4 \mathrm{ml}$ and $1.89 \mathrm{~L}) / \mathrm{ac}$ in $100 \mathrm{gal}(378.5 \mathrm{~L})$ of water at weekly intervals on 20 and 27 August and 2 and 9 September. Treatments had 20 beds (200' long and 44" wide) each and untreated control had 10 beds. Beauveria bassiana was applied by the farmer using tractor-mounted equipment. Insects were periodically monitored on 40 randomly selected plants from the middle 4 beds of the control plot and the middle 10 beds from each treatment plot. A beat tray was used to dislodge various pests from the sample plant and their numbers were counted. Insect populations were also monitored on a strip of flowering host plants such as alyssum, Lobularia maritima and wild mustard, Sinapis arvensis planted next to the control plot as a refuge for natural enemies.

\subsection{Efficacy of B. bassiana and azadirachtin against pests in greenhouse strawberries}

Greenhouse strawberries are not common in California, however, there was a farmer who had some pest issues on his strawberries grown experimentally in a greenhouse. This study was conducted in Nipomo, California in 2011. Treatments included a conventional formulation of $B$. bassiana (BotaniGard 22WP) at $1 \mathrm{lb}(453.6 \mathrm{~g}) / \mathrm{ac}$, spinoasad (Conserve SC) at $8 \mathrm{fl} \mathrm{oz}(236.6 \mathrm{ml}) / \mathrm{ac}$, azadirachtin (AzaSol) at $40 \mathrm{~g} / \mathrm{ac}$, spinosad (236.6 g/ac) along with azadirachtin $(30 \mathrm{~g} / \mathrm{ac})$, and an untreated control. Each treatment included $15^{\prime}$ long plots with four rows of strawberry plants. Treatments were replicated four times and arranged in a randomized complete block design. Materials were applied by the farmer using a backpack sprayer on 19 October and 15 November. Pest populations were monitored on five randomly selected plants in each plot using the beat trey method before, 3 or 4 days, and 7 days after each spray application. Data were subjected to general linear model of ANOVA and Tukey's HSD means separation test. 
Table 1

Cumulative daily mortality and corrected final mortality of adult L. hesperus from azadirachtin, B. bassiana, and chemical insecticides

\begin{tabular}{|c|c|c|c|c|c|c|}
\hline \multirow[t]{2}{*}{ Treatment } & \multicolumn{5}{|c|}{ Days after treatment } & \multirow[t]{2}{*}{ Corrected total mortality } \\
\hline & 1 & 2 & 3 & 4 & 5 & \\
\hline Untreated control & $0 \mathrm{c}^{*}$ & $2.5 \mathrm{c}$ & $5.0 \mathrm{e}$ & $5.0 \mathrm{c}$ & $10.0 \mathrm{e}$ & \\
\hline Thiomethoxam & $12.5 \mathrm{c}$ & $20.0 \mathrm{bc}$ & $37.5 \mathrm{bcde}$ & $42.5 \mathrm{bc}$ & $42.5 \mathrm{~cd}$ & $37.4 \mathrm{~cd}$ \\
\hline Azadirachtin & $2.5 \mathrm{c}$ & $5.0 \mathrm{c}$ & $12.5 \mathrm{e}$ & $20.0 \mathrm{c}$ & 30.0de & $25.6 \mathrm{~d}$ \\
\hline B. bassiana & $5.0 \mathrm{c}$ & $7.5 \mathrm{c}$ & $22.5 \mathrm{de}$ & $70.0 \mathrm{ab}$ & $100.0 \mathrm{a}$ & $100.0 \mathrm{a}$ \\
\hline Fenpropathrin & $15.0 \mathrm{c}$ & $20.0 \mathrm{bc}$ & $25.0 \mathrm{cde}$ & $32.5 \mathrm{bc}$ & $37.5 \mathrm{de}$ & $33.2 \mathrm{~d}$ \\
\hline Naled & $55.0 \mathrm{ab}$ & $57.5 \mathrm{ab}$ & $57.5 \mathrm{abcd}$ & $62.5 \mathrm{ab}$ & $70.0 \mathrm{bc}$ & $67.2 \mathrm{bc}$ \\
\hline Thiomethoxam + B. bassiana & $20.0 \mathrm{c}$ & $40.0 \mathrm{abc}$ & $70.0 \mathrm{ab}$ & $95.0 \mathrm{a}$ & $100.0 \mathrm{a}$ & $100.0 \mathrm{a}$ \\
\hline Azadirachtin $+B$. bassiana & $0 \mathrm{c}$ & $5.0 \mathrm{c}$ & $12.5 \mathrm{e}$ & $72.5 \mathrm{ab}$ & $100.0 \mathrm{a}$ & $100.0 \mathrm{a}$ \\
\hline Fenpropathrin $+B$. bassiana & $27.5 \mathrm{bc}$ & $50.0 \mathrm{ab}$ & $80.0 \mathrm{a}$ & $100.0 \mathrm{a}$ & $100.0 \mathrm{a}$ & $100.0 \mathrm{a}$ \\
\hline Naled + B. bassiana & $60.0 \mathrm{a}$ & $60.0 \mathrm{a}$ & $65.0 \mathrm{abc}$ & $67.5 \mathrm{ab}$ & $87.5 \mathrm{ab}$ & $85.5 \mathrm{ab}$ \\
\hline
\end{tabular}

* Means followed by the same letter within each column are not significantly different by Tukey's HSD $(P>0.05)$.

\section{Results}

\subsection{Improving the efficacy of B. bassiana with chemical insecticides}

Low rates of chemical insecticides and azadirachtin resulted in low mortality of adult L. hesperus (Table 1). All treatments that included B. bassiana except for its combination with naled caused $100 \%$ mortality. There were significant differences in cumulative daily mortality as well as total mortality among treatments $(P<0.05)$. The concentration of $B$. bassiana used is expected to cause high mortality in L. hesperus by the end of the assay. Combining low doses of chemical insecticides with $B$. bassiana significantly $(P<0.05)$ improved the mortality rate during the first three days after treatment. However, azadirachtin did not improve the mortality rate of B. bassiana. By adding thiamethoxam to $B$. bassiana, there was a $15.0,32.5,47.5(P=0.005)$, and $25.0 \%$ increase in the mortality during the four days after treatment. During the same period, fenpropathrin increased the mortality by $22.5,42.5$ $(P=0.01), 57.5(P=0.005)$ and $30.0 \%$. A higher improvement in $L$. hesperus mortality was, however, realized by naled with $55.0(P=0.0001), 52.5 \%(P=0.0004)$, and $42.5 \%(P=0.002)$ increase than $B$. bassiana alone on the first three days, respectively.

\subsection{Beauveria bassiana as an endophyte in strawberry plants}

Both the commercial and California isolates of $B$. bassiana endophytically colonized roots, petioles, pedicels, leaves, sepals, and calyxes of strawberry (Fig. 1). Fungus was recovered from these parts for up to nine weeks after inoculation. Observations could not be continued beyond nine weeks as all the plants were utilized for destructive sampling. There was no significant difference among different conidial concentrations for both isolates although proportion of colonized tissue was higher with increased concentration for the commercial isolate, GHA (Table 2). When the average for all plant parts was considered, significantly higher $(P=0.03)$ colonization was noticed at $10^{11}$ than $10^{9}$ conidia/ml for GHA.

In general, B. bassiana moved up from roots to petioles and leaves with time especially for the commercial isolate (Fig. 1, Table 2). When the results were combined for the entire observation period, significant differences were only seen at $10^{10}$ conidia/ml concentration for GHA where fungus colonized more leaves, sepals, and calyxes than roots $(P=0.01)$. There were no differences in the colonization of different plant parts by SfBb1 isolate.

\subsection{Field efficacy of B. bassiana}

Effect of the treatments on L. hesperus and aphids was not clear, but there seemed to be fewer F. occidentalis and T. vaporariorum in treated plots towards the end of the observation period (data not shown). However, there was a 


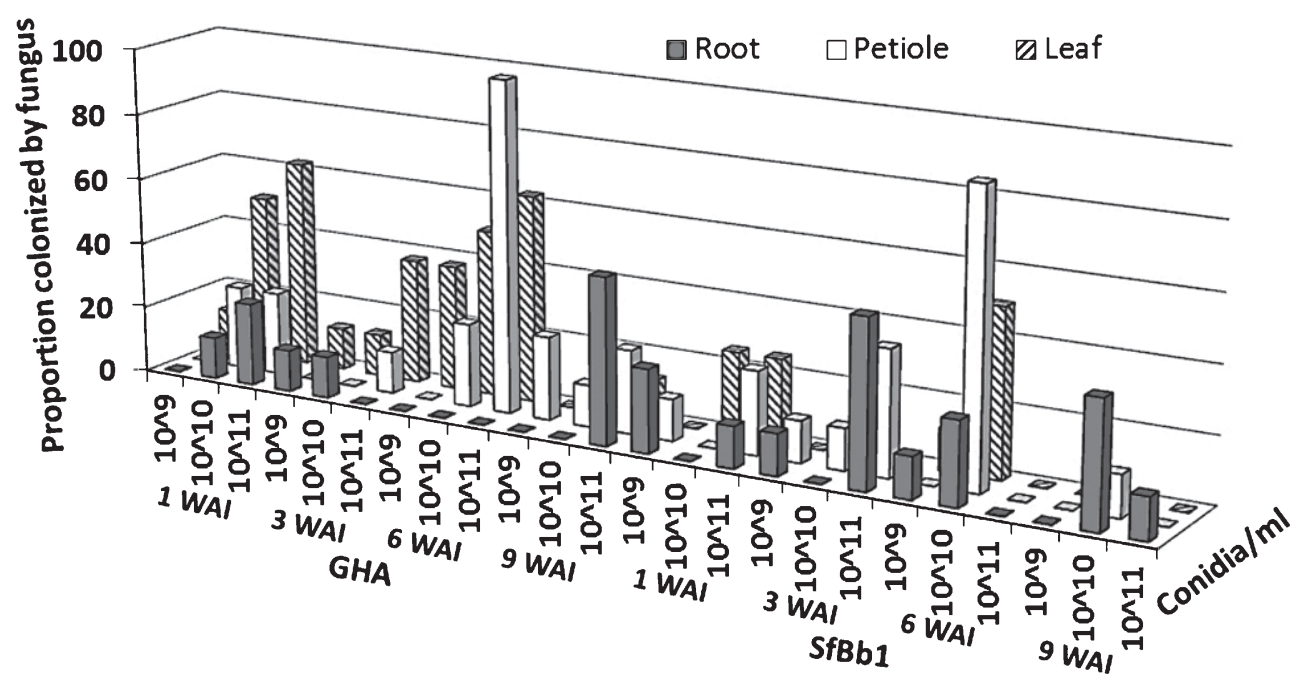

Fig. 1. Proportion of various plant parts endophytically colonized by commercial (GHA) and California (SfBb1) isolates of B. bassiana at 1 , 3 , 6, and 9 weeks after inoculation (WAI). Petiole includes pedicel and leaf includes sepal and calyx.

Table 2

Endophytic colonization of strawberry plant parts by commercial (GHA) and California (SfBb1) isolates of B. bassiana at various conidial concentrations

\begin{tabular}{|c|c|c|c|c|c|}
\hline Isolate & $\begin{array}{c}\text { Concentration } \\
\text { (Conidia/ml) }\end{array}$ & Root & Petiole & Leaf & Average \\
\hline \multirow[t]{3}{*}{ GHA } & $10^{9}$ & 3.1 & 12.5 & 18.8 & $11.5 b^{*}$ \\
\hline & $10^{10}$ & $6.3 \mathrm{~B}^{* *}$ & $15.6 \mathrm{AB}$ & $40.6 \mathrm{~A}$ & $20.8 \mathrm{ab}$ \\
\hline & $10^{11}$ & 18.8 & 50.0 & 43.8 & $37.5 \mathrm{a}$ \\
\hline \multirow[t]{3}{*}{ SfBb1 } & $10^{9}$ & 12.5 & 6.3 & 3.1 & 7.3 \\
\hline & $10^{10}$ & 15.6 & 28.1 & 18.8 & 20.8 \\
\hline & $10^{11}$ & 25.0 & 18.8 & 9.4 & 17.7 \\
\hline GHA & Combined & 9.4 & 26.0 & 34.4 & 23.3 \\
\hline SfBb1 & Combined & 17.7 & 17.7 & 10.4 & 15.3 \\
\hline
\end{tabular}

*Average colonization of all plant parts for GHA isolate was significantly different at different concentrations $P=0.03$ ). Means followed by the same lowercase letter in the column were not significantly different. ${ }^{* *}$ Colonization was significantly different among different plant parts at $10^{10}$ conidia/ml for GHA $(P=0.01)$. Means followed by the same uppercase letter in the row were not significantly different.

$50 \%$ reduction in lygus adults on alternate flowering hosts near the experimental plots during this time (Fig. 2). There was some reduction in 4 th and 5 th instar nymphs as well.

\subsection{Efficacy of azadirachtin and B. bassiana in the greenhouse}

Very low numbers of $L$. hesperus were found during this study and the effect of treatments could not be detected (data not shown). Beauveria bassiana, spinosad, and azadirachtin appeared to have an impact on aphids, F. occidentalis, and T. vaporariorum (Table 3). Statistically significant differences $(P<0.05)$ were found only for aphids 3 days after the second spray and aphids 7 days after the first spray. Aphid numbers were reduced in plots treated with $B$. bassiana and azadirachtin by 7 days after treatment (DAT) during the first spray. Following the second spray, reduction in aphids was seen only by azadirachtin however all other treatments seemed to prevent the build-up compared to a $106 \%$ increase in untreated control. 


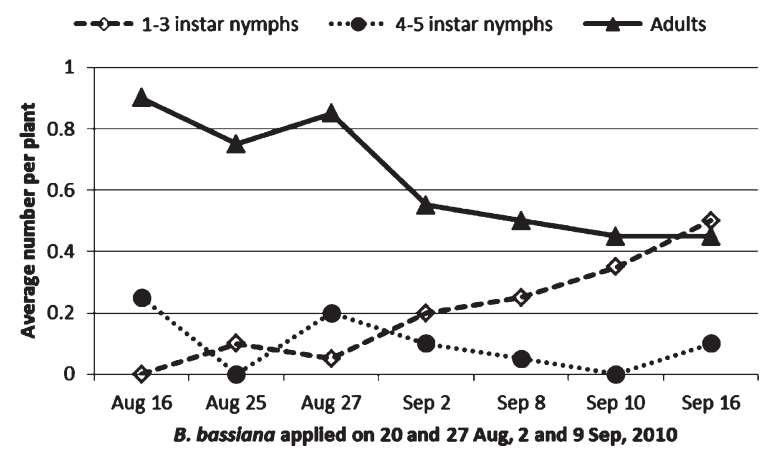

Fig. 2. Lygus hesperus populations on alternate flowering hosts in a strawberry field.

Table 3

Average number of aphids, western flower thrips, and greenhouse whitefly adults before and after the spray applications and per cent change by 7 days after treatment (DAT) compared to pre-treatment counts

\begin{tabular}{|c|c|c|c|c|c|c|c|c|}
\hline \multirow[t]{2}{*}{ Treatment } & \multicolumn{4}{|c|}{ After 1st application } & \multicolumn{4}{|c|}{ After 2nd application } \\
\hline & Pre-treat & 4DAT & 7DAT & $\%$ Change & Pre-treat & 3DAT & 7DAT & $\%$ Change \\
\hline \multicolumn{9}{|l|}{ Aphids } \\
\hline Untreated & 13.8 & 17.0 & 17.0 & 23.6 & 48.8 & $76.3 b$ & 100.3 & 105.6 \\
\hline B. bassiana & 17.0 & 20.5 & 10.0 & -41.2 & 55.8 & $76.3 b$ & 74.5 & 33.6 \\
\hline Spinosad & 17.3 & 17.3 & 21.3 & 23.2 & 83.3 & $146.3 \mathrm{a}$ & 100.5 & 20.7 \\
\hline Azadirachtin & 21.3 & 17.3 & 16.0 & -24.7 & 80.0 & $97.3 b$ & 71.3 & -10.9 \\
\hline Spin. + Aza. & 10.3 & 16.0 & 11.0 & 7.3 & 61.5 & $97.3 b$ & 71.0 & 15.4 \\
\hline \multicolumn{9}{|l|}{ F. occidentalis } \\
\hline Untreated & 33.8 & 8.8 & 7.0ab* & -79.3 & 19.0 & 12.0 & 14.8 & -22.4 \\
\hline B. bassiana & 30.3 & 8.3 & $4.3 b$ & -86.0 & 25.0 & 11.3 & 9.3 & -63.0 \\
\hline Spinosad & 37.8 & 7.3 & $7.5 \mathrm{ab}$ & -80.1 & 23.5 & 15.5 & 15.3 & -35.1 \\
\hline Azadirachtin & 36.5 & 13.3 & $15.8 \mathrm{a}$ & -56.8 & 16.8 & 21.5 & 16.0 & -4.5 \\
\hline Spin. + Aza. & 42.0 & 6.3 & $6.8 \mathrm{ab}$ & -83.9 & 26.0 & 24.3 & 10.0 & -61.5 \\
\hline \multicolumn{9}{|c|}{ T. vaporariorum } \\
\hline Untreated & 2.8 & 3.0 & 3.5 & 27.3 & 5.3 & 8.0 & 9.3 & 76.2 \\
\hline B. bassiana & 4.8 & 3.5 & 3.5 & -26.3 & 13.0 & 11.5 & 10.8 & -17.3 \\
\hline Spinosad & 3.8 & 4.0 & 3.5 & -6.7 & 7.3 & 15.0 & 12.8 & 75.9 \\
\hline Azadirachtin & 4.5 & 3.8 & 2.5 & -44.4 & 13.0 & 14.3 & 13.5 & 3.8 \\
\hline Spin. + Aza. & 3.5 & 2.3 & 4.8 & 35.7 & 5.0 & 11.8 & 8.5 & 70.0 \\
\hline
\end{tabular}

* Means followed by the same letter within each column are significantly different $(P<0.05)$.

There was a general decline in thrips populations during the observation period. However, there was a higher reduction in plots treated with $B$. bassiana and the combination of spinosad and azadirachtin. Whitefly populations were initially low and gradually increased during the observation period. There was a $44 \%$ reduction from azadirachtin followed by $26 \%$ from $B$. bassiana and $7 \%$ from spinosad after the first spray. After the second spray, B. bassiana reduced whitefly adults by $17 \%$ while azadirachtin limited the increase to $4 \%$. There was $70 \%$ or more increase in the rest of the treatments.

\section{Discussion}

Strawberries are cultivated in about 38,000 acres in California and nearly $90 \%$ are grown using conventional practices [6]. Chemical pesticides are primarily used for managing various arthropod pests with the exception of 
Bacillus thuringiencis against lepidopteran pests early during the production season. According to the California Department of Pesticide Regulation data, 257,118 lb $(115,300 \mathrm{~kg})$ of insecticide active ingredients was used in 2011. Pests such as L. hesperus, T. urticae, and T. vaporariorum are often difficult to control with current practices. Continuous use of chemical pesticides also leads to the build-up of resistant populations of some of these pests occasionally and warrants the need for alternative control measures. Organic farmers face even a bigger challenge with limited options to manage pests.

Although environmental conditions in the strawberry growing regions of California are ideal for entomopathogenic fungi, which are generally pathogenic to various strawberry pests, lack of information on efficacy mainly limited their use. These studies were aimed at investigating the potential of non-chemical alternatives such as B. bassiana and azadirachtin for managing various arthropod pests on strawberries.

\subsection{Combining chemical and biopesticides}

The objective of this study was to improve the efficacy of B. bassiana with low doses of chemical insecticides commonly used in strawberries against $L$. hesperus adults. Although azadirachtin is primarily used as an insect growth regulator targeting immature stages, it was included in this study because of its antifeedant activity [18]. Entomopathogenic fungi require a few days for the conidia to penetrate the host cuticle, invade the tissues, and eventually kill the host. Adding low doses of chemical insecticides is expected to weaken the insect or stimulate the growth of fungus and thus improve the efficacy of B. bassiana. Synergism between the neonicotinoid insecticide, imidacloprid and the entomopathogenic fungi, Metarhizium anisopliae (Metschn.) Sorokin, Beauveria bassiana, Hirsutella thompsonii Fisher was reported against various pests around the world [10, 12, 22, 27]. Compared to the mortality caused by B. bassiana during the first few days after inoculation, addition of thiamethoxam, fenpropathrin, and naled increased the mortality in L. hesperus in the current study.

In most cases, biopesticides are not the first choice for the farmers because of their high cost, sensitivity to harsh environmental conditions, slow response, and the general perception that they are less effective than chemical insecticides. This study suggests that entomopathogenic fungi such as B. bassiana can offer a potential control option for the strawberry farmers. Using the fungus with low rates of chemical insecticides can contribute to the reduction of chemical insecticide use, increase the efficacy of pest management that is difficult with individual options, and improvement of the environmental safety through integrated pest management.

\subsection{Endophytic colonization of strawberry plants by B. bassiana}

Previous studies indicate that B. bassiana enters the cuticle and colonizes the tissues of various plant species including banana [3], cocoa [19], coffee [20], corn [26], and tomato [15] and provide insect control possibly through feeding deterrence or antibiosis [7, 25]. Toxic metabolites in B. bassiana are thought to have negative impact on the herbivores feeding on the colonized plants. This study demonstrates for the first time that B. bassiana colonizes various strawberry tissues and persisted for up to nine weeks. The impact of endophytic fungus on strawberry pests is yet to be determined. A greenhouse study with strawberries is currently under investigation using $M$. persicae as a model insect. Preliminary observations indicate that soil inoculation of B. bassiana contributes to aphid mortality [8].

For the practical purpose, fungus can be introduced by various means into the strawberry plants. Dipping the roots of the strawberry transplants in the conidial suspension of $B$. bassiana at the time of planting can help with the early establishment of fungus and early season protection. In a recently completed study, inoculating the roots of strawberry transplants with $B$. bassiana significantly improved the growth and health of the plants compared to an untreated control and a microbe-based plant growth enhancer [8]. Various formulations can also be administered through drip irrigation system or by foliar application. Use of the plastic mulch to cover the beds and the spread of the plant canopy close to the bed will provide additional protection to the inoculum in the soil or under the canopy from environmental conditions. With the foundation of the current findings and the study currently under investigation, the potential of endophytic B. bassiana for pest control will be determined in the near future. 


\subsection{Field efficacy of B. bassiana}

Conducting field studies on commercial fields for a high value crop such as strawberry poses some challenges especially when experimenting with materials of unknown or questionable efficacy. This study was conducted towards the end of the growing season on cut-back strawberry plants. As a result, foliage was not extensive and insect populations were also low. Temperatures are generally higher during this time of the year compared to the main growing season and there were a few days with more than average temperatures during the study period. Although environmental and crop conditions were not ideal, this study was initiated to take advantage of the interest of a collaborative farmer. Harsh environment, lack of dense foliage to protect the fungal inoculum, and low pest populations could have contributed to inconclusive results. However, reduction in $L$. hesperus adult populations on alternate flowering hosts could have been from insects moving from the treated plots probably carrying fungal inoculum to the alternate hosts. Some farmers maintain strips of flowering hosts near strawberry fields to provide a refuge to the natural enemies and usually higher numbers of $L$. hesperus are seen on these plants than on strawberry. Younger nymphs are usually less susceptible to the fungal infection due to their frequent molting and hence the effect of $B$. bassiana on their numbers could not be seen in the flowering hosts. However, large and small plot studies conducted in the following years suggested that $B$. bassiana and azadirachtin can be a potential option for strawberry pest management. Combination of $B$. bassiana and azadirachtin appeared suppress $L$. hesperus populations and $B$. bassiana provided control comparable to chemical miticides against T. urticae in studies conducted in 2012 [9].

\section{Conclusions}

These studies are crucial in evaluating the potential of non-chemical alternatives for strawberry pest management as this information was previously not available. Botanical and microbial pesticides either alone or when aided with chemical or other options can provide effective pest control. Rotating or combining these materials with chemical insecticides will provide a sustainable solution for pest management.

\section{Acknowledgments}

We would like to thank Dale Spurgeon, USDA-ARS, Shafter for providing greenhouse and laboratory facilities for some of the studies and Neal Hudson for the technical assistance. We would also like to thank Dave Peck, Manzanita Berry Farms, Santa Maria and Ivor Van Wingerden, Ocean Breeze Flowers, Nipomo for their collaboration in field and greenhouse studies.

\section{References}

[1] Abbott WS. A method of computing the effectiveness of insecticide. J Econ Entomol. 1925;18(2):265-7.

[2] Ahmad N, Ansari MS, Hasan F. Effects of neem based insecticides on Plutella xylostella (Linn.). Crop Protection. 2012;34:18-24.

[3] Akello J, Dubois T, Coyne D, Kyamanywa S. Endophytic Beauveria bassiana in banana (Musa spp.) reduces banana weevil (Cosmopolites sordidus) fitness and damage. Crop Protection 2008;27(11):1437-41.

[4] Bing LA, Lewis LC. Suppression of Ostrinia nubilalis (Hübner) (Lepidoptera: Pyralidae) by endophytic Beauveria bassiana (Balsamo) Vuillemin. Environ Entomol. 1991;20(4):1207-11.

[5] California Department of Pesticide Regulation. Summary of pesticide use report data 2011 indexed by commodity. 2011; CDPR, Sacramento, CA.

[6] California Strawberry Commission. Acreage survey-update. 2012; CSC, Watsonville, CA.

[7] Cherry AJ, Banito A, Djegui D, Lomer C. Suppression of the stem-borer Sesamia calamistis (Lepidoptera; Noctuidae) in maize following seed dressing, topical application and stem injection with African isolates of Beauveria bassiana. Intl J Pest Management. 2004;50(1): $67-73$.

[8] Dara SK. Whiteflies impact strawberries as a pest and a disease vector. Central Coast Agriculture Highlights, 2013 ; July issue, 1-2.

[9] Dara SK. Microbial control as an important component of strawberry IPM. CAPCA Adviser. 2013;XVI(1):29-32. 
[10] Dara SK, Hountondji FCC. Effects of formulated imidacloprid on two mite pathogens, Neozygites floridana (Zygomycotina: Zygomycetes) and Hirsutella thompsonii (Deuteromycotina: Hyphomycetes). Intl J Trop Ins Sci. 2001;21(2):133-8.

[11] Furlong MJ, Groden E. Evaluation of synergistic interactions between the Colorado potato beetle (Coleoptera: Chrysomelidae) pathogen Beauveria bassiana and the insecticides, imidacloprid, and cyromazine. J Econ Entomol. 2001;94(2):344-56.

[12] Kaakeh W, Reid BL, Bohnert TJ, Bennett GW. Toxicity of imidacloprid in the German cockroach (Dictyoptera, Blattellidae), and the synergism between imidacloprid and Metarhizium anisopliae (Imperfect fungi, Hyphomycetes). J Econ Entomol. 1997;90(2):473-82.

[13] Karnavar GK. Influence of azadirachtin on insect nutrition and reproduction. Proc Ind Acad Sci-Animal Sci. 1987;96(3):341-7.

[14] Kovach J, English-Loeb G. Using Beauveria bassiana to manage tarnished plant bug in strawberries. 1996 NYS Fruit Project Reports, no. 1997;213:52-4.

[15] Leckie BM. Effects of Beauveria bassiana mycelia and metabolites incorporated into synthetic diet and fed to larval Helicoverpa zea, and detection of endophytic Beauveria bassiana in tomato plants using PCR and ITS. MS thesis, Department of Entomology, The University of Tennessee. 2002.

[16] Ludwig SW, Oetting RD. Efficacy of Beauveria bassiana plus insect attractants for enhanced control of Frankliniella occidentalis (Thysanoptera: Thripidae). Fla Entomol. 2002;85(1):270-2.

[17] McGuire MR, Leland JE, Dara SK, Park Y-H, Ulloa M. Effect of different isolates of Beauveria bassiana on field populations of Lygus hesperus. Biol Control. 2006;38(3):390-6.

[18] Mordue (Luntz) AJ, Blackwell A. (1993). Azadirachtin: An update. J Ins Physiol. 1993;39(1):903-24.

[19] Posada F, Vega FE. Establishment of the fungal entomopathogen Beauveria bassiana (Ascomycota: Hypocreales) as an endophyte in cocoa seedlings (Theobroma cacao). Mycologia. 2005;97(6):1195-200.

[20] Posada F, Aime MC, Peterson SW, Rehner SA, Vega FE. Inoculation of coffee plants with the fungal entomopathogen Beauveria bassiana (Ascomycota: Hypocreales). Mycol Res. 2007;111(6):749-58.

[21] Quesada-Moraga E, Maranhao EAA, Valverde-García P, Santiago-Álvarez C. Selection of Beauveria bassiana isolates for control of the whiteflies Bemisia tabaci and Trialeurodes vaporariorum on the basis of their virulence, thermal requirements, and toxicogenic activity. Biol Control. 2006;36(3):274-87.

[22] Quintela ED, McCoy C. Pathogenicity enhancement of Metarhizium anisopliae and Beauveria bassiana to first instars of Diaprepes abbreviatus (Coleoptera, Curculionidae) with sublethal doses of imidacloprid. Environ Entomol. 1997;26(5):1173-82.

[23] Schmutterer H. Properties and potential of natural pesticides from the neem tree, Azadirachta indica. Ann Rev Entomol. 1990;35:271-97.

[24] Shi W-B, Zhang L-L, Feng M-G. Field trials of four formulations of Beauveria bassiana and Metarhizium anisopliae for control of cotton spider mites (Acari: Tetranychidae) in the Tarim Basin of China. Biol Control. 2008;45(1):48-55.

[25] Vega FE, Posada F, Aime MC, Pava-Ripoll M, Infante F, Rehner SA. Entomopathogenic fungal endophytes. Biol Control. 2008;46(1):72-82.

[26] Wagner BL, Lewis L. C. Colonization of corn, Zea mays, by the entomopathogenic fungus Beauveria bassiana. Appl Environ Microbiol. 2000;66(8):3468-73.

[27] Ye S-D, Du Y-H, Feng M-G. Time and concentration dependent interactions of Beauveria bassiana with sublethal rates of imidacloprid against the aphid pests Macrosiphoniella sanborni and Myzus persicae. Ann Appl Biol. 2005;146(4):459-68.

[28] Ying S, Feng M, Xu S, Ma Z. Field efficacy of emulsifiable suspensions of Beauveria bassiana conidia for control of Myzus persicae population on cabbage. Ying Yong Sheng Tai Xue Bao 2003;14(4):545-8. 